\title{
PET/CT of breast cancer regional nodal recurrences: an evaluation of contouring atlases
}

Laura Beaton ${ }^{1}$, Luminita Nica ${ }^{1}$, Scott Tyldesley ${ }^{1,2}$, Kenny Sek$^{3}$, Gareth Ayre ${ }^{1}$, Maria Aparicio ${ }^{1}$, Lovedeep Gondara ${ }^{2}$, Caroline Speers ${ }^{2}$ and Alan Nichol $^{1,2^{*}}$ (D)

\begin{abstract}
Background: To validate the Radiation Therapy Oncology Group (RTOG) and European Society for Radiotherapy and Oncology (ESTRO) breast cancer nodal clinical target volumes (CTVs) and to investigate the Radiotherapy Comparative Effectiveness Consortium (RADCOMP) Posterior Neck volume in relation to regional nodal recurrences (RNR).

Methods: From a population-based database, 69 patients were identified who developed RNR after curative treatment for breast cancer. RNRs were detected with 18-fluorodeoxyglucose-positron emission tomographycomputed tomography (PET/CT). All patients were treatment-naïve for RNR when imaged. The RTOG and ESTRO nodal CTVs and RADCOMP Posterior Neck volumes were contoured onto a template patient's CT. RNRs were contoured on each PET/CT and deformed onto the template patient's CT. Each RNR was represented by a $5 \mathrm{~mm}$ diameter epicentre, and categorized as 'inside', 'marginal' or 'outside' the CTV boundaries.

Results: Sixty-nine patients with 226 nodes (median 2, range 1-11) were eligible for inclusion. Thirty patients had received adjuvant tangent and regional nodal radiotherapy, 16 tangent-only radiotherapy and 23 no adjuvant radiotherapy. For the RTOG CTVs, the RNR epicentres were 70\% (158/226) inside, 4\% (8/226) marginal and 27\% (60/ 226) outside. They included the full extent of the RNR epicentres in $38 \%(26 / 69)$ of patients. Addition of the RADCOMP Posterior Neck volume increased complete RNR coverage to 48\% (33/69) of patients. For the ESTRO CTVs, the RNR epicentres were 73\% (165/226) inside, 2\% (4/226) marginal and 25\% (57/226) outside. They included the full extent of the RNR epicentres in 57\% (39/69) of patients. Addition of the RADCOMP Posterior Neck volume increased complete RNR coverage to 70\% (48/69) of patients.

Conclusions: The RTOG and ESTRO breast cancer nodal CTVs do not fully cover all potential areas of RNR, but the ESTRO nodal CTVs provided full coverage of all RNR epicentres in 19\% more patients than the RTOG nodal CTVs. With addition of the RADCOMP Posterior Neck volume to the ESTRO CTVs, 70\% of patients had full coverage of all RNR epicentres.
\end{abstract}

\footnotetext{
* Correspondence: anichol@bccancer.bc.ca

'Department of Radiation Oncology, BC Cancer, Vancouver Centre, Vancouver, British Columbia, Canada

${ }^{2}$ Cancer Surveillance and Outcomes, BC Cancer, Vancouver Centre, Vancouver, British Columbia, Canada

Full list of author information is available at the end of the article
}

(c) The Author(s). 2020 Open Access This article is licensed under a Creative Commons Attribution 4.0 International License, which permits use, sharing, adaptation, distribution and reproduction in any medium or format, as long as you give appropriate credit to the original author(s) and the source, provide a link to the Creative Commons licence, and indicate if changes were made. The images or other third party material in this article are included in the article's Creative Commons licence, unless indicated otherwise in a credit line to the material. If material is not included in the article's Creative Commons licence and your intended use is not permitted by statutory regulation or exceeds the permitted use, you will need to obtain permission directly from the copyright holder. To view a copy of this licence, visit http://creativecommons.org/licenses/by/4.0/ The Creative Commons Public Domain Dedication waiver (http://creativecommons.org/publicdomain/zero/1.0/) applies to the data made available in this article, unless otherwise stated in a credit line to the data. 


\section{Introduction}

Regional nodal relapse (RNR) is an important predictor of breast cancer-specific (BCSS) and overall survival [1]. It is well established that adjuvant breast/chest wall radiotherapy (RT) reduces the risk of relapse and improves overall survival [1, 2]. Furthermore, for high-risk patients, RT to the regional lymph nodes improves local control, reduces distant metastases, and improves overall survival [1, 3-5]. More recently, data from the EORTC 22922-10925, MA.20, and DBCG-IMN trials showed a benefit of regional nodal irradiation (RNI) even in early-stage breast cancer [6-8]. As a result, an increasing number of patients are receiving adjuvant RNI. In this context, it is imperative to cover the volume containing microscopic disease without irradiating unnecessarily large nodal clinical target volumes (CTVs). Furthermore, the effort to better map RNRs is particularly important as the use of intensitymodulated RT (IMRT) and proton beam therapy for breast cancer becomes more common.

In 2009, the Radiation Therapy Oncology Group (RTOG) published a consensus guideline to improve the accuracy of nodal target delineation and reduce individual inconsistencies in contouring $[9,10]$. In 2015, the European Society for Radiotherapy and Oncology (ESTRO) published a consensus guideline which differed from the RTOG atlas. Its purpose was to create a nodal CTV that matched the historical treatment volume of 3D conformal locoregional breast radiotherapy. Compared to the RTOG CTV, it added $0.5 \mathrm{~cm}$ lateral and medial margins on the IMC vessels, added an interpectoral nodal CTV between the pectoralis major and minor, and reduced the cranial border of the supraclavicular fossa (SCF) CTV from the cricoid cartilage to $0.5 \mathrm{~cm}$ cranial to the subclavian vein $[11,12]$. Since then, a number of studies have evaluated the location of RNRs in relation to the RTOG Breast Cancer Atlas [13-19] and the ESTRO Breast Cancer Atlas [17-21], noting that their supraclavicular CTVs have poor coverage of diseased posterior neck lymph nodes (Table 1). Some studies have mapped areas of RNR onto a template patient with the atlases already contoured [13, 15-20], but few have used deformable registration [19]. Furthermore, most of these prior studies identified RNRs with computerized tomography (CT), which is inferior to 18fluorodeoxyglucose positron emission tomography/

Table 1 Studies of regional nodal relapses in relation to nodal contouring atlases

\begin{tabular}{|c|c|c|c|c|c|c|c|c|c|}
\hline & $\begin{array}{l}\text { Total no. } \\
\text { patients } \\
\text { (nodes) }\end{array}$ & $\begin{array}{l}\text { Inclusion } \\
\text { criteria }\end{array}$ & $\begin{array}{l}\text { No. relapsed } \\
\text { patients } \\
\text { (nodes) }\end{array}$ & $\begin{array}{l}\text { Nodal } \\
\text { area } \\
\text { assessed }\end{array}$ & $\begin{array}{l}\text { No. patients } \\
\text { received } \\
\text { adjuvant RNI }\end{array}$ & $\begin{array}{l}\text { Imaging } \\
\text { technique for } \\
\text { relapse }\end{array}$ & $\begin{array}{l}\text { Nodal mapping } \\
\text { technique }\end{array}$ & $\begin{array}{l}\text { Nodal } \\
\text { contours or } \\
\text { epicentres }\end{array}$ & $\begin{array}{l}\text { Nodal } \\
\text { Atlases } \\
\text { Studied }\end{array}$ \\
\hline $\begin{array}{l}\text { Brown et al. } \\
2015 \text { [13] }\end{array}$ & $62(161)$ & $\begin{array}{l}\text { De novo } \\
\text { and } \\
\text { relapse }\end{array}$ & $18(44)$ & SCF & 4 & $\begin{array}{l}\text { CT/PET } \\
\text { or MRI }\end{array}$ & $\begin{array}{l}\text { Manual mapping } \\
\text { Template patient }\end{array}$ & Epicentre & RTOG \\
\hline $\begin{array}{l}\text { Gentile et al. } \\
2015 \text { [14] }\end{array}$ & 30 (309) & $\begin{array}{l}\text { De novo } \\
\text { only }\end{array}$ & $0(0)$ & Axilla & NA & CT scan & $\begin{array}{l}\text { Rigid fusion } \\
\text { Individual }\end{array}$ & Contours & RTOG \\
\hline $\begin{array}{l}\text { Jing et al. } \\
2015 \text { [15] }\end{array}$ & $55(524)$ & $\begin{array}{l}\text { De novo } \\
\text { and } \\
\text { relapse }\end{array}$ & 38 (NA) & SCF & 3 & $\begin{array}{l}\text { CT scan or } \\
\text { FDG/PET }\end{array}$ & $\begin{array}{l}\text { Manual mapping } \\
\text { Template patient }\end{array}$ & $\begin{array}{l}\text { Epicentres + } \\
\text { contours }\end{array}$ & RTOG \\
\hline $\begin{array}{l}\text { Jethwa et al. } \\
2016 \text { [16] }\end{array}$ & $130(67)$ & $\begin{array}{l}\text { De novo } \\
\text { and } \\
\text { relapse }\end{array}$ & $7(15)$ & IMN & NA & $\begin{array}{l}\text { CT, PET/CT or } \\
M R I\end{array}$ & $\begin{array}{l}\text { Manual mapping } \\
\text { Template patient }\end{array}$ & Epicentres & RTOG \\
\hline $\begin{array}{l}\text { Chang et al. } \\
2017 \text { [17] }\end{array}$ & $129(235)$ & $\begin{array}{l}\text { Relapse } \\
\text { only }\end{array}$ & $129(235)$ & All & 49 & CT scan & $\begin{array}{l}\text { Manual mapping } \\
\text { Template patient }\end{array}$ & Epicentres & $\begin{array}{l}\text { RTOG } \\
\text { ESTRO }\end{array}$ \\
\hline $\begin{array}{l}\text { Chang et al. } \\
2018 \text { [18] }\end{array}$ & 234 (337) & $\begin{array}{l}\text { Relapse } \\
\text { only }\end{array}$ & 234 (337) & All & 130 & $\begin{array}{l}\text { CT scan or } \\
\text { PET/CT }\end{array}$ & $\begin{array}{l}\text { Manual mapping } \\
\text { Template patient }\end{array}$ & Epicentres & $\begin{array}{l}\text { RTOG } \\
\text { ESTRO }\end{array}$ \\
\hline $\begin{array}{l}\text { Borm et al. } \\
2018 \text { [19] }\end{array}$ & $235(580)$ & $\begin{array}{l}\text { De novo } \\
\text { and } \\
\text { relapse }\end{array}$ & 197 (410) & All & NA & PET/CT & $\begin{array}{l}\text { Deformable } \\
\text { registration } \\
\text { Template patient }\end{array}$ & Contours & $\begin{array}{l}\text { RTOG } \\
\text { ESTRO }\end{array}$ \\
\hline $\begin{array}{l}\text { Deselm } \\
\text { et al. } 2018 \\
\text { [20] }\end{array}$ & $153(243)$ & $\begin{array}{l}\text { Relapse } \\
\text { only }\end{array}$ & $153(243)$ & All & NA & $\begin{array}{l}C T, P E T / C T \text { or } \\
M R I\end{array}$ & $\begin{array}{l}\text { Manual mapping } \\
\text { Template patient }\end{array}$ & Epicentres & $\begin{array}{l}\text { RTOG } \\
\text { ESTRO }\end{array}$ \\
\hline $\begin{array}{l}\text { Kowlaski } \\
\text { et al. } 2019 \\
{[22]}\end{array}$ & 102 (389) & $\begin{array}{l}\text { Not } \\
\text { stated }\end{array}$ & Not stated & All & NA & $\mathrm{PET} / \mathrm{CT}$ & $\begin{array}{l}\text { Manual mapping } \\
\text { Template patient }\end{array}$ & Epicentres & $\begin{array}{l}\text { RTOG } \\
\text { ESTRO } \\
\text { RADCOMP }\end{array}$ \\
\hline $\begin{array}{l}\text { Almahariq } \\
\text { et al. } 2020 \\
{[21]}\end{array}$ & 106 (107) & $\begin{array}{l}\text { De novo } \\
\text { only }\end{array}$ & $0(0)$ & $\begin{array}{l}\text { Axilla } \\
\text { Level I }\end{array}$ & NA & $\begin{array}{l}\text { CT or PET, } \\
\text { Biopsy Clip }\end{array}$ & $\begin{array}{l}\text { Manual mapping } \\
\text { Template patient }\end{array}$ & Epicentres & $\begin{array}{l}\text { RTOG } \\
\text { ESTRO } \\
\text { RADCOMP }\end{array}$ \\
\hline $\begin{array}{l}\text { Current } \\
\text { study }\end{array}$ & $69(226)$ & $\begin{array}{l}\text { Relapse } \\
\text { only }\end{array}$ & $69(226)$ & All & 30 & $\mathrm{PET} / \mathrm{CT}$ & $\begin{array}{l}\text { Deformable } \\
\text { registration } \\
\text { Template patient }\end{array}$ & Epicenters & $\begin{array}{l}\text { RTOG } \\
\text { ESTRO } \\
\text { RADCOMP }\end{array}$ \\
\hline
\end{tabular}


computed tomography (PET/CT) [23, 24]. Many studies included patients with de novo nodal disease, on the assumption that areas harboring gross disease at presentation are those same regions most likely to harbor microscopic disease needing adjuvant radiotherapy [13-16, 19]. However, we felt that a study examining RNR alone would provide valuable information about the greatest possible extent of microscopic disease at presentation. Thus, we set out to validate the RTOG and ESTRO nodal CTVs. The RADCOMP atlas was developed for breast cancer patients requiring locoregional RT in the RTOG 3510 phase III clinical trial of conventional RT versus proton RT [25]. We also wanted to explore the benefit of using the RADCOMP Posterior Neck volume for covering RNR outside of the RTOG and ESTRO supraclavicular nodal CTVs [25].

\section{Materials and methods}

\section{Patient population}

Between July 2005 and March 2013, all patients treated curatively with a diagnosis of invasive breast cancer that had undergone PET/CT were identified from a population-based database. During this time period, contouring regional nodes for radiotherapy planning was not routine at our institution. All PET/CTs were performed for restaging at the time of clinically detected RNR. Patients were included if they had a diagnosis of RNR (defined as $\left[{ }^{18} \mathrm{~F}\right]$ fluorodeoxyglucose (FDG)-avid tissue in ipsilateral regional lymph nodes) with or without distant metastatic relapse, and if FDG PET/CT was performed $>6$ months after initial curative surgery (to exclude those likely to have had macroscopic disease during their curative treatment). Patients were excluded if macroscopic disease was detected at time of RT planning, if a new primary breast cancer was diagnosed, or if they had undergone any treatment for RNR prior to PET/CT to ensure we had a cohort of patients with unperturbed RNR. Patient, tumor and treatment details, as well as clinical outcomes were obtained from the Breast Cancer Outcomes Unit which maintains a prospectively collected database.

\section{Regional nodal mapping}

The RTOG and ESTRO breast cancer nodal CTVs and the RADCOMP Posterior Neck volume were contoured by radiation oncologists ( $\mathrm{LB}$ and $\mathrm{AN}$ ) onto a radiotherapy planning $\mathrm{CT}$ of a template patient who was scanned on a 12.5-degree breast board. At the time of CTV contouring, LB and AN were blinded to the FDG uptake on the PET/CTs. The PET/CT showing RNR for each patient was loaded onto the MIM planning system (version 6.4, MIM Software Inc., Cleveland, OH). FDG-avid nodes were included as RNRs if they had FDG uptake on PET/CT with a corresponding lymph node on CT/ PET and were reported as abnormal by a nuclear medicine physician. FDG-avid RNRs were contoured by a nuclear medicine specialist (KS) and radiation oncologist (LB) using the MIM PET Edge ${ }^{\mathrm{Tm}}$ contour tool, a gradient-based technique that draws a threshold surface defined by the steepest drop off in standardized uptake values. The Edge tool generates reproducible contours that correspond to the anatomic size and location of the corresponding masses on CT [26]. Using the MIM software, a deformable registration algorithm was used to deform each contoured FDG-avid RNR onto the template patient's planning CT, with the RTOG-CTV, ESTRO-CTV and RADCOMP Posterior Neck volume already outlined. The position of each deformed RNR was visually reviewed, and edited, if necessary, to ensure accurate localization. The spherical growth pattern of breast cancer metastases in regional lymph nodes is an established imaging feature that is used to distinguish between normal and diseased lymph nodes [27, 28]. Hence, on the understanding that large RNRs started growing from a small nidus of disease, a $5 \mathrm{~mm}$ sphere was created at the mathematical centroid of the RNR to represent the location of microscopic disease at presentation. Relapses were mapped according to whether the patient had received RNI, tangent only RT or no RT.

\section{Analysis of atlas coverage}

Each RNR epicentre was assessed in relation to the contoured RTOG, ESTRO and RADCOMP Posterior Neck CTVs. Coverage for each RNR was defined as: 'inside', 'marginal' or 'outside'. In keeping with previous trials, locations of RNR were defined as 'inside': entirely or mostly within the CTVs, 'marginal': mostly outside the CTV edges, and 'outside': completely outside the CTV contours [13]. For 'marginal' or 'outside' epicentres, the location of RNR relative to the CTVs was recorded.

\section{Statistical analyses}

Descriptive statistics and analyses were performed using Fisher's exact tests for continuous variables and $x^{2}$ test for categorical variables. Univariate logistic regression was used to assess the association of these baseline patient/tumor factors: number of positive nodes, grade, stage, lymphovascular invasion and use of adjuvant RNI. Two-sided $p$-values $<0.05$ were considered statistically significant. Statistical analysis was performed using SAS version 9.3 (SAS Institute, Cary $\mathrm{NC}$ ) and $\mathrm{R}$ 3.2.3. This study was reviewed and approved by the BC Cancer Research Ethics Board.

\section{Results}

\section{Patient characteristics}

Between 2005 and 2013, 1071 patients underwent PET/ CT for breast cancer. Figure 1 details how our cohort of 69 eligible patients was selected. Baseline patient, tumor 


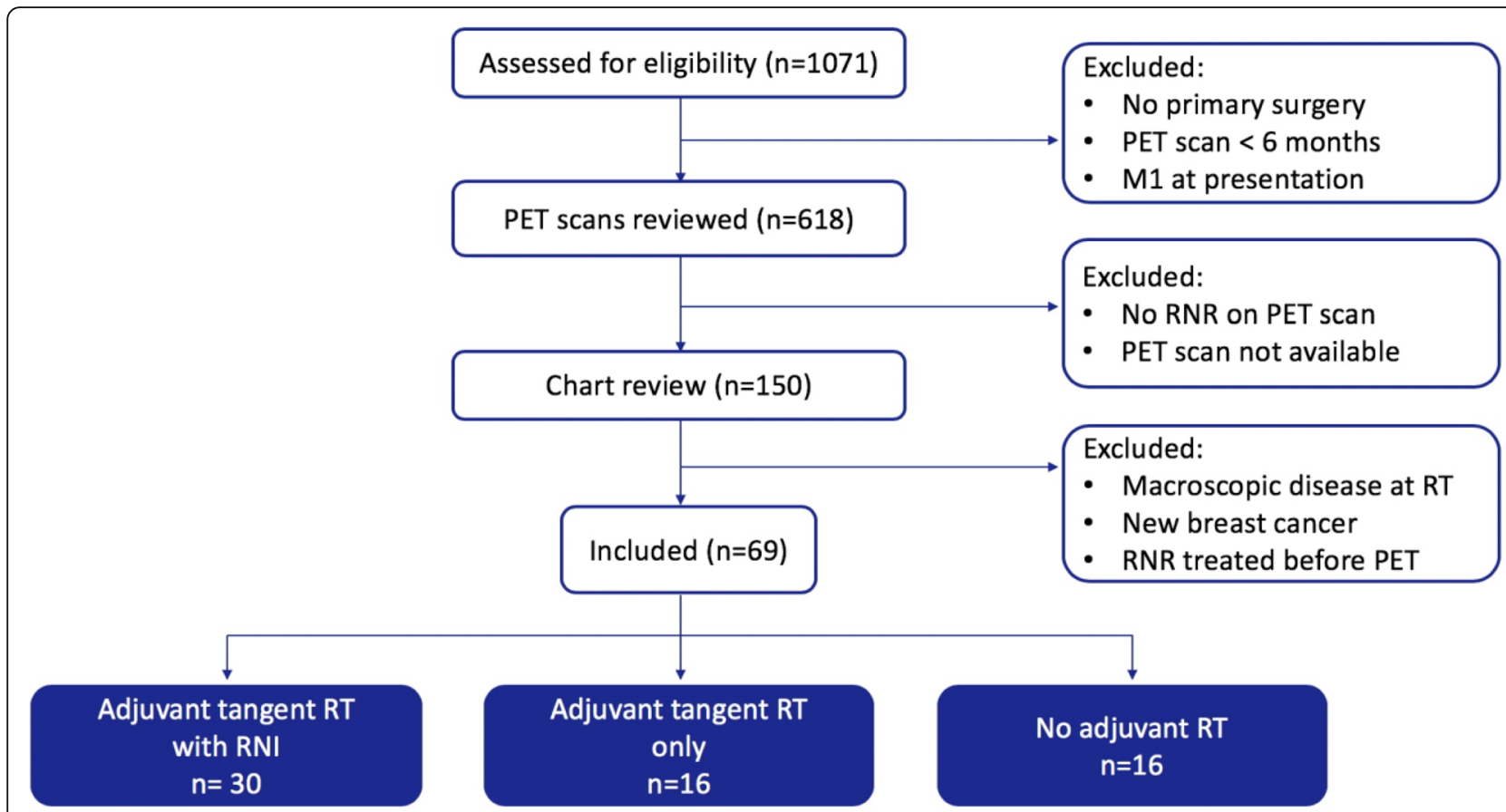

Fig. 1 Study schema. Abbreviations: PET, 18-fluorodeoxyglucose-positron emission tomography-computed tomography; RNI, regional lymph node irraditaion; RT, radiotherapy; $R N R$, regional nodal relapse

and treatment details, as well as relapse data are shown in Table 2. In total, 226 FDG-positive RNRs were identified in 69 patients (range 1-11, median 2 RNR/patient, mean $3.3 \mathrm{RNR} /$ patient). Ninety-three percent (64/69) of patients had biopsies to confirm relapse: 28 of regional nodes, 22 of breast/chest wall and 14 of distant sites. Thirty-eight patients (55\%) had distant metastatic disease at the time of RNR, whilst 31 patients (45\%) had RNR without distant metastases. Regarding initial adjuvant treatment, 30 patients had 3/4-field RNI to the breast/chest wall region and the supraclavicular lymph nodes (including 28 patients with axillary RT and 12 patients with RT to the first three interspaces of the IMCs); 16 patients had tangent-only RT (including two patients who received wide-tangent $\mathrm{RT}$ covering the IMN chain without axillary/supraclavicular RT); and 23 patients had no RT.

\section{Coverage of regional nodes at relapse}

For the RTOG CTVs, the RNR epicentres were $70 \%$ $(158 / 226)$ inside, $4 \%(8 / 226)$ marginal and $27 \%(60 / 226)$ outside. They included the full extent of the RNR epicentres in $38 \%(26 / 69)$ of patients. Addition of the RADCOMP Posterior Neck volume increased complete RNR coverage to $48 \%(33 / 69)$ of patients. For the ESTROCTVs, the RNR epicentres were 73\% (165/226) inside, $2 \%(4 / 226)$ marginal and $25 \%(57 / 226)$ outside. They included the full extent of the RNR epicentres in 57\% (39/ 69) of patients. Addition of the RADCOMP Posterior
Neck volume increased complete RNR coverage to $70 \%$ $(48 / 69)$ of patients.

\section{Location of regional nodes at relapse}

Figure 2 shows the location of all contoured nodes and epicentres by adjuvant treatment. An anatomic atlas of the 226 RNR, coded by initial treatment, is available in the supplemental material. The sites of RNR were: axilla level I $(n=64,28 \%)$, followed by axilla level II $(n=37$, $16 \%$ ), SCF (anterior neck, $n=35,15 \%$ ), axilla level II $(n=35,15 \%)$, IMN region $(n=34,15 \%)$ and RADCOMP Posterior Neck $(n=21,9 \%)$. Table 3 summarises the location of epicentres that were marginal/outside the RTOG and ESTRO-CTVs. For the RTOG SCF RNRs, $48 \%$ of epicentres were inside the SCF-CTV. Among the outside/marginal SCF epicentres, 18 were located posterior to the SCF-CTV in the Posterior Neck volume of the RADCOMP atlas. For the axillary RNRs, 91\% of level I, $68 \%$ of level II, and $80 \%$ of level III epicentres were inside the axillary CTVs. Among the outside/marginal axillary epicentres, 12 were located caudal to the RTOG level II CTV. For the IMN RNRs, 68\% of epicentres were inside the IMN CTV. Among the outside/marginal IMN epicentres, 7 were medial to the RTOG-CTV. Relapses in the interpectoral nodes were coded as outside the RTOG-CTV. Seventy-five percent (168/226) of RNRs were within the ESTRO-CTVs. For the ESTRO-SCF RNRs, 39\% were inside the SCF CTV. Among the outside/marginal SCF epicentres, 18 were in the Posterior 
Table 2 Patient and tumor baseline characteristics and locations of nodal relapses

\begin{tabular}{|c|c|c|c|c|c|c|}
\hline & & $\begin{array}{l}\text { All patients } \\
\boldsymbol{N}=69\end{array}$ & $\begin{array}{l}\mathrm{RNI} \\
\boldsymbol{N}=30\end{array}$ & $\begin{array}{l}\text { Tangent only } \\
\boldsymbol{N}=16\end{array}$ & $\begin{array}{l}\text { No RT } \\
\boldsymbol{N}=23\end{array}$ & $\boldsymbol{P}$-value \\
\hline $\begin{array}{l}\text { Age } \\
\text { Median (Range) }\end{array}$ & & $49(29-84)$ & $48.5(30-76)$ & $52(35-75)$ & $48(29-84)$ & 0.45 \\
\hline \multirow[t]{2}{*}{ Laterality } & Right & $34(49 \%)$ & $14(47 \%)$ & $8(50 \%)$ & $12(52 \%)$ & 0.92 \\
\hline & Left & $35(51 \%)$ & $16(53 \%)$ & $8(50 \%)$ & $11(48 \%)$ & \\
\hline \multirow[t]{4}{*}{ Grade } & 1 & $6(9 \%)$ & $1(3 \%)$ & $1(6 \%)$ & $4(17 \%)$ & 0.27 \\
\hline & 2 & 27 (39\%) & $11(37 \%)$ & $8(50 \%)$ & $8(35 \%)$ & \\
\hline & 3 & $32(46 \%)$ & 17 (57\%) & $6(38 \%)$ & $9(40 \%)$ & \\
\hline & Unknown & $4(4 \%)$ & $1(3 \%)$ & $1((6 \%)$ & $2(9 \%)$ & \\
\hline \multirow[t]{4}{*}{ Tumor size } & $0-2 \mathrm{~cm}$ & $32(46 \%)$ & $10(33 \%)$ & $11(69 \%)$ & $11(48 \%)$ & 0.03 \\
\hline & $>2-5 \mathrm{~cm}$ & $26(38 \%)$ & $12(40 \%)$ & $5(31 \%)$ & $9(40 \%)$ & \\
\hline & $>5 \mathrm{~cm}$ & $9(14 \%)$ & $8(27 \%)$ & $0(0 \%)$ & $1(4 \%)$ & \\
\hline & Unknown & $2(3 \%)$ & $0(0 \%)$ & $0(0 \%)$ & $2(9 \%)$ & \\
\hline \multirow[t]{4}{*}{ Number of positive nodes } & 0 & $32(46 \%)$ & $5(17 \%)$ & $14(88 \%)$ & $13(57 \%)$ & $<0.01$ \\
\hline & $1-3$ & 19 (28\%) & $13(43 \%)$ & $2(12 \%)$ & $4(17 \%)$ & \\
\hline & $\geq 4$ & 14 (20\%) & 11 (37\%) & $0(0 \%)$ & $3(13 \%)$ & \\
\hline & Unknown & $4(6 \%)$ & $1(3 \%)$ & $0(0 \%)$ & $3(13 \%)$ & \\
\hline \multirow[t]{4}{*}{ Stage } & I & $24(35 \%)$ & $6(20 \%)$ & $6(38 \%)$ & $12(52 \%)$ & $<0.01$ \\
\hline & II & $28(40 \%)$ & 16 (54\%) & $6(38 \%)$ & $6(26 \%)$ & \\
\hline & III & $6(9 \%)$ & $4(13 \%)$ & $0(0 \%)$ & $2(9 \%)$ & \\
\hline & Unknown & $11(16 \%)$ & $4(13 \%)$ & $4(24 \%)$ & $3(13 \%)$ & \\
\hline \multirow[t]{3}{*}{ Her2 status } & Positive & $6(9 \%)$ & $4(13 \%)$ & $1(6 \%)$ & $1(4 \%)$ & 0.54 \\
\hline & Negative & $40(58 \%)$ & 19(63\%) & $9(56 \%)$ & $12(52 \%)$ & \\
\hline & Unknown & 23 (33\%) & $7(23 \%)$ & $6(38 \%)$ & $10(44 \%)$ & \\
\hline \multirow[t]{3}{*}{ Estrogen status } & Positive & 47 (68\%) & 17 (57\%) & $12(75 \%)$ & 18 (78\%) & 0.11 \\
\hline & Negative & 20 (29\%) & 13 (43\%) & $3(19 \%)$ & $4(17 \%)$ & \\
\hline & Unknown & $2(3 \%)$ & $0(0 \%)$ & $1(6 \%)$ & $1(4 \%)$ & \\
\hline \multirow[t]{2}{*}{ Surgery } & BCS & 31 (45\%) & 10 (33\%) & 13 (81\%) & $8(35 \%)$ & $<0.01$ \\
\hline & Mastectomy & $38(55 \%)$ & $20(66 \%)$ & $3(19 \%)$ & 15 (65\%) & \\
\hline \multirow[t]{2}{*}{ Axillary lymph node dissection } & Yes & $53(77 \%)$ & 27 (90\%) & $12(75 \%)$ & $14(61 \%)$ & 0.04 \\
\hline & No & $16(23 \%)$ & $3(10 \%)$ & $4(25 \%)$ & $9(31 \%)$ & \\
\hline \multirow[t]{2}{*}{ Chemotherapy } & Yes & $46(67 \%)$ & $23(77 \%)$ & $12(75 \%)$ & $11(48 \%)$ & 0.07 \\
\hline & No & $23(33 \%)$ & $7(23 \%)$ & $4(25 \%)$ & $12(52 \%)$ & \\
\hline \multirow[t]{2}{*}{ Hormone therapy } & Yes & 41 (59\%) & $16(53 \%)$ & $12(75 \%)$ & $13(57 \%)$ & 0.14 \\
\hline & No & $28(41 \%)$ & $14(47 \%)$ & $4(25 \%)$ & $10(43 \%)$ & \\
\hline \multirow{2}{*}{$\begin{array}{l}\text { Isolated RNR } \\
\text { RNR and distant metastases }\end{array}$} & & $31(45 \%)$ & $9(30 \%)$ & $9(56 \%)$ & $13(57 \%)$ & 0.09 \\
\hline & & $38(55 \%)$ & $21(70 \%)$ & $7(44 \%)$ & $10(43 \%)$ & \\
\hline Number of RNR & & 226 & 92 & 48 & 86 & \\
\hline RNR per Patient & & 3.3 & 3.1 & 3.0 & 3.7 & 0.28 \\
\hline RNR Locations & $\begin{array}{l}\text { SCF } \\
\text { (CTV4) }\end{array}$ & 35 & 20 & 7 & 8 & \\
\hline \multirow[t]{4}{*}{ (ESTRO CTV) } & Axilla Level 1 (CTV1) & 64 & 22 & 15 & 27 & \\
\hline & Axilla Level 2 (CTV2) & 27 & 7 & 8 & 12 & \\
\hline & Interpectoral & 11 & 5 & 1 & 5 & \\
\hline & Axilla Level 3 (CTV3) & 34 & 12 & 6 & 16 & \\
\hline
\end{tabular}


Table 2 Patient and tumor baseline characteristics and locations of nodal relapses (Continued)

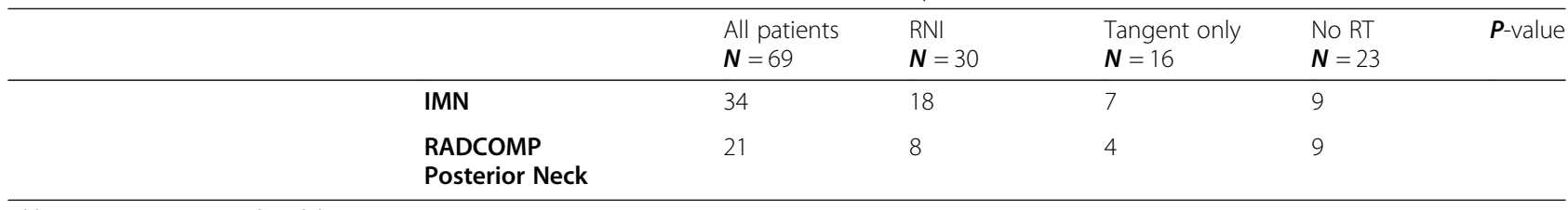

Abbreviation: RNR Regional nodal recurrence

Neck volume of the RADCOMP atlas and 5 were cranial to the ESTRO-SCF CTV, but within the RTOG SCF CTV. For the axillary RNRs, $87 \%$ of level I, 78\% of level II, and $85 \%$ of level III epicentres were inside the axillary CTVs. Eleven RNRs were within the interpectoral CTV. Among the outside/marginal axillary epicentres, 3 were posterior to the ESTRO level I CTV, but within the RTOG level I CTV. For the IMN RNRs, $85 \%$ of epicentres were inside the IMN CTV. Among the outside/marginal IMN epicentres, 3 were medial to the ESTRO-CTV.

\section{Factors related to CTV coverage}

To determine which node-positive patients need more extensive nodal coverage, associations between baseline variables and RNR epicentres being marginal/outside of the ESTRO-CTV were analysed using univariable logistic regression. We report our analysis of geographic misses cranial to the SCF-CTV or in the posterior neck in Table 4. There was no significant association between geographic miss for the baseline variables: grade, LVI, use of RNI, type of relapse, or stage. However, the odds ratio of having supra-ESTRO SCF-CTV or RADCOMP Posterior Neck RNRs was elevated: 3.3 (0.4-29.0, $p=$ 0.28 ) for patients with stage 3 vs stage $1-2$ disease.

\section{Discussion}

In this study, we used PET/CT to create a comprehensive atlas of RNR after curative treatment. Strengths of our study include exclusive use of PET/CT and our well-defined cohort of relapse-only patients who were imaged before any salvage treatment. Our study showed that SCF RNR coverage by the SCF-CTVs was poor: only $48 \%$ for the RTOG atlas and only $39 \%$ for the ESTRO atlas. Almost one-third of the supraclavicular RNR outside of the RTOG and ESTRO SCF-CTVs were located within the RADCOMP Posterior Neck volume [25]. The ESTRO IMC-CTV is $5 \mathrm{~mm}$ wider than the RTOG IMCCTV, the ESTRO axilla Level II is more generous inferiorly than the RTOG axilla level II CTV and the ESTRO interpectoral CTV covered RNR missed by the RTOG-

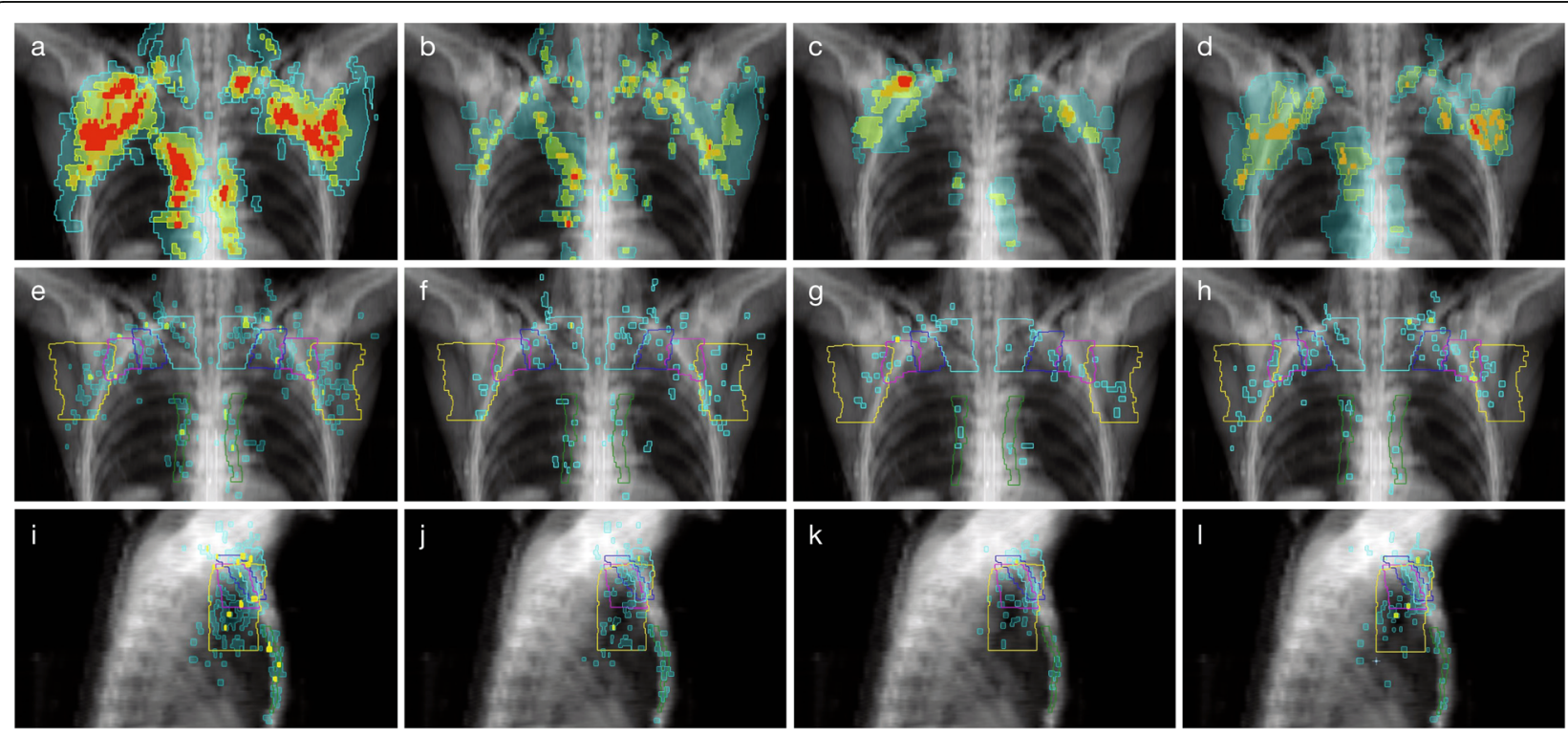

Fig. 2 Anterior and lateral views of RNRs and RNR epicentres. Anterior view of contoured RNRs (a-d)*: a all patients, b nodal RT, c tangents $\mathbf{d}$ no RT; anterior view of RNR epicentres (e-h)*\#: e all patients, $\mathbf{f}$ nodal RT, $\mathbf{g}$ tangents, $\mathbf{h}$ no RT; lateral view of RNR epicentres (i-I)**: i all patients, $\mathbf{j}$ nodal RT, $\mathbf{k}$ tangents, I no RT. *Colour scheme of overlap of contoured nodes: Blue = one node, yellow = overlap of two nodes, Orange = overlap of three nodes, Red = overlap of four nodes. "Colour scheme of RTOG-CTVs: Cyan = Supraclavicular; Yellow = Axilla level I; Magenta = Axilla level II; Blue = Axilla level III; Green = IMC 
Table 3 Locations of epicentres that were marginal or outside of RTOG and ESTRO Nodal CTVs

\begin{tabular}{|c|c|c|c|c|c|c|c|c|c|c|}
\hline \multirow[t]{2}{*}{ RTOG CTVs } & \multirow[b]{2}{*}{$\begin{array}{l}\text { RNR } \\
n=226\end{array}$} & \multicolumn{3}{|c|}{$\begin{array}{l}\text { Classification of RNRs } \\
\text { (Percentage for RTOG CTV) }\end{array}$} & \multicolumn{6}{|c|}{$\begin{array}{l}\text { Direction of Marginal or Outside RNR compared to RTOG CTVs } \\
\text { Number (Percentage of all } 68 \text { Marginal and Outside RNRs) }\end{array}$} \\
\hline & & $\begin{array}{l}\text { Outside } \\
n=60\end{array}$ & $\begin{array}{l}\text { Marginal } \\
n=8\end{array}$ & $\begin{array}{l}\text { Inside } \\
n=158\end{array}$ & Cranial & Caudal & Anterior & Posterior & Lateral & Medial \\
\hline SCF & 56 & $28(50 \%)$ & $1(2 \%)$ & $27(48 \%)$ & $5(7 \%)$ & & & $21(31 \%)^{*}$ & $3(4 \%)$ & \\
\hline Axilla level I & 64 & $6(9 \%)$ & 0 & $58(91 \%)$ & $1(1 \%)$ & $1(1 \%)$ & $1(1 \%)$ & $1(1 \%)$ & $2(3 \%)$ & \\
\hline Axilla level II & 37 & $11(30 \%)$ & $1(3 \%)$ & $25(68 \%)$ & $3(4 \%)$ & $12(18 \%) \dagger$ & $2(3 \%)$ & & & \\
\hline Axilla level III & 35 & $9(17 \%)$ & $1(3 \%)$ & $25(80 \%)$ & $3(4 \%)$ & $3(4 \%)$ & & $1(1 \%)$ & $1(1 \%)$ & $2(3 \%)$ \\
\hline IMC & 34 & $6(18 \%)$ & $5(15 \%)$ & $23(68 \%)$ & & $2(3 \%)$ & & & $2(3 \%)$ & $7(10 \%)$ \\
\hline * RADCOMP Posterior Neck & 21 & $3(14 \%)^{\circ}$ & 0 & $18(86 \%)$ & $3(100 \%)$ & & & & & \\
\hline \multirow[t]{2}{*}{ ESTRO-CTVs } & & \multicolumn{3}{|c|}{$\begin{array}{l}\text { Classification of RNRs } \\
\text { (Percentage for ESTRO-CTV) }\end{array}$} & \multicolumn{6}{|c|}{$\begin{array}{l}\text { Direction of Marginal or Outside RNR compared to ESTRO-CTVs } \\
\text { Number (Percentage of all } 61 \text { Marginal and Outside RNRs) }\end{array}$} \\
\hline & $\begin{array}{l}\text { RNR } \\
n=226\end{array}$ & $\begin{array}{l}\text { Outside } \\
n=57\end{array}$ & $\begin{array}{l}\text { Marginal } \\
n=4\end{array}$ & $\begin{array}{l}\text { Inside } \\
n=165\end{array}$ & Cranial & Caudal & Anterior & Posterior & Lateral & Medial \\
\hline SCF & 56 & $33(59 \%)$ & $1(2 \%)$ & $22(39 \%)$ & $9(15 \%)$ & & & $21(34 \%)^{*}$ & $3(5 \%)$ & $1(2 \%)$ \\
\hline Axilla Level I & 64 & $8(13 \%)$ & 0 & $56(87 \%)$ & $1(1 \%)$ & $1(1 \%)$ & $1(1 \%)$ & $4(7 \%)$ & $1(1 \%)$ & \\
\hline Axilla Level II & 27 & $6(22 \%)$ & 0 & $21(78 \%)$ & $3(5 \%)$ & $1(1 \%)$ & & $2(3 \%)$ & & \\
\hline Interpectoral & 11 & 0 & 0 & $11(100 \%)$ & & & & & & \\
\hline Axilla Level III & 34 & $7(12 \%)$ & $1(3 \%)$ & $26(85 \%)$ & $3(5 \%)$ & $3(5 \%)$ & & & & $2(3 \%)$ \\
\hline $\mathrm{IMC}$ & 34 & $3(9 \%)$ & $2(6 \%)$ & $29(85 \%)$ & & $2(3 \%)$ & & & & $3(3 \%)$ \\
\hline * RADCOMP Posterior Neck & 21 & $3(14 \%)^{\circ}$ & 0 & $18(86 \%)$ & $3(100 \%)$ & & & & & \\
\hline
\end{tabular}

Abbreviation: RNR Regional nodal recurrence

CTV. We observed that these differences were responsible for the per-patient increase in coverage of all RNRs from $38 \%$ of patients by the RTOG-CTV to $57 \%$ of patients with the ESTRO-CTV. Addition of the RADCOMP Posterior Neck volume increased coverage of all RNRs to $48 \%$ for the RTOG-CTV and to $70 \%$ for the ESTRO-CTV.

There are four studies that have mapped the location of RNRs in relation to the RTOG nodal atlas using a mixture of patients at diagnosis and at relapse, imaged with CT or PET/CT [13-16]. Two studies focused on
SCF coverage: Jing et al demonstrated that the RTOG SCF CTV covered $62.6 \%$ of SCF epicentres across all patients and all SCF epicentres in $25.5 \%$ of patients, whilst Brown et al showed that the RTOG SCF CTV covered $59 \%$ of SCF epicentres $[13,15]$. In our study, the RTOG SCF CTV covered only $48 \%$ (27/56) of epicentres, possibly because our cohort was entirely relapsed patients. A third study by Jethwa et al evaluated IMN epicentres and reported $53 \%$ overall coverage with $19 \%$ of IMN nodes located medial to the RTOG IMN CTV [16]. In our study, $18 \%(6 / 34)$ of the IMN marginal/outside

Table 4 Univariable logistic regression analysis of risk factors for regional nodal recurrences superior to the ESTRO supraclavicular CTV (CTV4) or in the RADCOMP Posterior Neck CTV in patients who were treated for node-positive breast cancer $(n=33)$

\begin{tabular}{|c|c|c|c|}
\hline Baseline Variable & Odds ratio & 95\% confidence interval & $p$-value \\
\hline \multicolumn{4}{|l|}{ Lymphovascular invasion* } \\
\hline Yes vs No & 1.8 & $0.3-10.9$ & 0.52 \\
\hline \multicolumn{4}{|l|}{ Grade* } \\
\hline 3 vs $1 \& 2$ & 0.6 & $0.1-3.0$ & 0.56 \\
\hline \multicolumn{4}{|l|}{ Stage* } \\
\hline ||l vs | \& || & 3.3 & $0.4-29.0$ & 0.28 \\
\hline \multicolumn{4}{|c|}{ Adjuvant regional nodal radiotherapy } \\
\hline Yes vs No & 0.7 & $0.1-3.5$ & 0.63 \\
\hline \multicolumn{4}{|l|}{ Type of relapse } \\
\hline Metastatic \& RNR vs RNR only & 0.6 & $0.1-3.0$ & 0.56 \\
\hline
\end{tabular}

Abbreviation: RNR Regional nodal recurrence. *Unknowns removed before statistical analyses 
epicentres were medial to the RTOG IMN CTV, which includes only the vessels. Jethwa et al suggested adding a $4 \mathrm{~mm}$ margin transversely to the RTOG IMN CTV. The caudal border of the RTOG level II CTV was highlighted as a high-risk area by Gentile et al, who showed that $80 \%$ of uncovered level II RNR were located caudal to the RTOG level II CTV [14]. Similarly, 71\% (12/17) of our level II 'marginal/outside' epicentres were located caudally.

Borm et al studied patients with both primary and recurrent disease by contouring the nodes with FDG uptake on CT/PET and deformably mapping them onto the CT of a template patient with the atlases contoured [19]. They excluded lymph nodes with volume $>20 \mathrm{~cm}^{3}$, corresponding to an equivalent spherical recurrence of $3.3 \mathrm{~cm}$ diameter. In the 197 patients with 410 RNR (mean $2.1 \mathrm{RNR} /$ patient), $27.3 \%$ of nodes were $95 \%$ covered, $52.2 \%$ of nodes had $5-95 \%$ coverage and $20.5 \%$ of nodes were $<5 \%$ covered by the RTOG-CTV. They also noted that a higher proportion of FDG-avid SCF and IMC nodes were observed in the relapse setting than for newly staged patients, for example, $19.5 \%$ of nodes were located in the SCF in patients with recurrent breast cancer, which was 5 times higher compared to patients with primary breast cancer. This is in keeping with our results: we found that $25 \%$ of RNRs were in the SCF.

DeSelm et al studied 243 RNR in 153 patients (mean 1.6 RNR/patient) using an unreported mix of CT and PET imaging by manually transferring the location of RNR epicentres onto a template patient. They found that baseline LVI was associated with IMN RNR and that Grade 3 disease was associated with IMN and SCV RNR. The RTOGCTV encompassed $82 \%$ of RNR. In addition, the majority $67 \%(30 / 45)$ of out-field RNR were located in the lateral and posterior SCF region. They made an important observation that estrogen receptor-negative status, lymphovascular invasion, and grade 3 disease independently predicted SCV and IMN recurrence [20].

Chang et al studied 337 treatment-naive local and regional recurrences in 234 patients imaged with an unknown mix of CT and PET imaging [18]. There were 237 RNR in 162 patients (mean 1.5 RNR/patient). They reported differences in coverage between the RTOGCTV and the ESTRO-CTV in relation to the ESTROCTV. The ESTRO-CTV covered 100\% of Axilla Level 1, 94\% of Axilla Level II, 95\% of Axilla Level III and 100\% of IMC RNR. However, the coverage was not as good for the supraclavicular region: the ESTRO-SCF-CTV covered only $71 \%$ of SCF RNRs and, while the RTOGSCF-CTV covered an additional 9\% of SCF RNRs superior to the ESTRO-SCF-CTV, 20\% were outside both CTVs. We found that a similar 9\% (5/56) of SCF recurrences occurred superior to the ESTRO-SCF-CTV, but inside the RTOG-SCF-CTV. In our study, the RTOGSCF-CTV covered only $48 \%$ and the ESTRO-SCF-CTV covered only 39\% of SCF-RNR. This difference may be due to our exclusive use of PET/CT, which is superior to CT for detection of lymph node metastasis [24, 29, 30]. There may also have been a selection bias in the use of $\mathrm{PET} / \mathrm{CT}$ in our cohort, which is suggested by our patients having a median age of 49 years and our mean RNR/patient being more than double that in their study. Almahariq et al. studied the location of biopsied axillary level I lymph nodes at initial diagnosis in relation to the RTOG, ESTRO and RADCOMP atlases. The level 1 axillary CTVs covered $54-66 \%$ of the biopsied lymph nodes, because many were lateral and inferior to the axillary CTVs below the level of the clavicle. However, when the breast CTV was considered, $94 \%$ of the lymph nodes were covered by the RTOG atlas [21].

In our study, we confirmed that RNRs outside the RTOG and ESTRO-CTVs were common. Other studies have shown that the lateral and posterior aspects of the SCF are not well covered [13, 15, 17, 18, 20]. Previous suggestions to modify the SCF-CTVs have included; extending to the lateral-most extent of the scalene muscle, having a more generous coverage of the posterior SCF [13], and modifying the SCF to its natural anatomic barriers (encompassing the medial edge of the trapezius muscle, lateral edge of the thyroid gland, posterior edge of the SCM muscle and ventral edge of the trapezius muscle), which has been shown to encompass $96.1 \%$ of all nodes [15]. The "Posterior Neck" volume of the RADCOMP atlas and the "Lateral SCV" and "Posterior SCV" volumes in DeSelm et al's manuscript supplement both provide good descriptions of this important region of geographic miss.

Our study does have several limitations. Importantly, we cannot know whether we were studying RNR in lymph nodes that did not contain microscopic disease at presentation because the anatomic extent of nodal disease increased between the time of curative treatment and RNR detection. Hence, our reported extent of RNRs may be an overestimate of the extent of microscopic disease in typical patients at the time of treatment. In addition, our cohort included a number of patients initially treated in the 1990's when cytotoxic chemotherapy was less effective in an era when HER-2 testing and targeted therapies were not available. It is possible that the use of modern adjuvant therapies may have modified patterns of RNR. Also, although 1071 breast cancer patients underwent PET/CT in our study period, only 69 patients met inclusion criteria. Our sample size was further divided into three subsets that received different initial locoregional management, limiting our ability to study how initial treatments impacted relapse patterns.

In this study, RNRs were contoured using the highly reproducible PET Edge ${ }^{\text {Tm }}$ tool in the MIM software, which was calibrated so that the PET-generated 
contours matched the visible masses on CT. An alternative approach would have been to contour the FDG-avid RNRs using the CT scan alone. However, our approach was taken for a number of reasons. Firstly, we found that many axillary relapses were surrounded by surgical clips, meaning that the CT images were degraded by artefact, which would have led to a degree of uncertainty when contouring on CT alone. It is not unusual for a normal lymph node to measure $2 \mathrm{~cm}$ in the long axis, but to have eccentric FDG-uptake, for example, at one pole. Secondly, contouring of the entire lymph node, most of which is normal, on the CT scan would lead to a misrepresentation of relapse location. Trying to contour only part of the lymph node would lead to uncertainty about the edges of the relapse within the cortex of the lymph nodes because the density of normal lymph node cortex and metastatic disease are similar on CT. However, we did review the relationship between FDG-uptake and CT masses for every RNR and discovered that a small number of patients had moved between the attenuationcorrection CT and PET acquisition. For these cases, the RNRs were recontoured exclusively on the CT/PET thus improving the accuracy of our results. Furthermore, we decided to report on epicentre location as opposed to the location of the entire RNR contour. The majority of studies of regional nodal relapses after breast cancer treatment have also analysed the epicentres of contoured RNRs, but we do appreciate that other excellent studies have instead analysed the full extent of the contoured RNRs (Table 1). It is our personal observation that RNRs are usually spherical or ellipsoid in shape, in keeping with previous reports $[27,28]$. We therefore believe that the centroid of a focus of FDG uptake or a mass on CT is an imperfect, but adequate, surrogate for the original tumour nidus. However, for completeness, in Fig. 2a, we do illustrate the full extent of the contoured RNRs in our study.

With advanced radiotherapy techniques, such as IMRT and proton beam therapy being used for RNI, precise CTV target definition is important to ensure accurate dose delivery. Kowalski et al. published a study including 389 RNRs in 102 patients (3.8 RNR/patient) [22]. They compared the dosimetric coverage of FDG-avid lymph node metastases for plans created with the RTOG, ESTRO and RADCOMP atlases using 3D conformal, volumetricmodulated arc therapy (VMAT) and pencil-beam scanning proton therapy (PBSPT). Reassuringly, they found that $97 \%$ of RNR were covered by a conventional 3D conformal plan of partial wide tangents and APPA supraclavicular and axillary fields. With dose distributions optimized for each of the three atlases, the RNR coverage by VMAT plans was $89 \%$ for ESTRO, 93\% for RTOG and 98\% for RADCOMP and by PBSPT plans was $88 \%$ for ESTRO, 91\% for RTOG and 96\% for RADCOMP. Only the sophisticated plans generated using the RADCOMP atlas achieved superior coverage of RNRs to a conventional 3D conformal plan. Hence, the RADCOMP atlas seems to identify the volumes most at risk of RNR better than the RTOG and ESTRO atlases. However, larger irradiation volumes could lead to an increased risk of late toxicity, including carotid artery stenosis, lymphedema, cardiac injury or secondary malignancy [31-34], and the additional benefit would need to outweigh these risks. Perhaps only patients with high risk disease need radiotherapy planning to the RADCOMP nodal CTVs. Unfortunately, our analysis did not identify a baseline variable that would justify contouring a posterior neck volume when treatment planning node-positive patients. Larger studies with more power to analyse baseline characteristics in relation to RNR locations may be able to identify predictive variables.

There are two review articles about validation studies of breast cancer nodal CTVs. Gee et al. performed a comparison and systematic review of contouring consensus guidelines for breast cancer radiotherapy, including the RTOG, ESTRO and RADCOMP atlases [35]. They concluded that more generous CTVs may be recommended for patients with locally advanced disease. Loganadane et al. also compared the nodal target volumes of the RTOG, ESTRO and RADCOMP atlases [36]. They provided detailed visual and written details about the differences between the atlases and concluded that treatment planning for patients with locally advanced disease should use the RADCOMP atlas. Our study results are congruent with the opinions expressed in these review articles. We found that the RTOG atlas did not cover RNRs as well as the ESTRO atlas and that the ESTRO atlas did not cover RNRs as well as the RADCOMP atlas. We performed a logistic regression analysis to identify patients who were more likely to have RNRs superior to the ESTRO SCF and/or in the RADCOMP Posterior Neck. Although the odds ratio was not statistically significant in our study, stage III patients were more likely than stage II patients to have RNRs in these regions.

\section{Conclusions}

Our supplemental atlas of RNRs highlights areas at high risk of nodal relapse after curative treatment. The RTOG and ESTRO breast cancer nodal CTVs do not fully cover all potential areas of RNR, but the ESTRO nodal CTVs provided full coverage of all RNR epicentres in more patients than the RTOG nodal CTVs. With addition of the RADCOMP Posterior Neck volume to the ESTRO-CTVs, 70\% of patients had full coverage of all RNR epicentres. We recommend use of the RADCOMP atlas for Stage III patients.

\section{Supplementary information}

Supplementary information accompanies this paper at https://doi.org/10. 1186/s13014-020-01576-6.

Additional file 1. 


\section{Acknowledgements}

Not applicable.

\section{Authors' contributions}

$L B, S T, A N, G A, L N$ contributed to study design. LB, AN, LN, CS and GA were involved in data acquisition. LB, AN, ST, CS, LG were involved in data analysis and interpretation. $\mathrm{LB}, \mathrm{ST}$ and $\mathrm{AN}$ were responsible for writing the manuscript. All authors have reviewed and approved the final article.

\section{Funding}

This research did not receive any specific grant from funding agencies in the public, commercial, or not-for-profit sectors.

\section{Availability of data and materials}

The datasets used and/or analysed during the current study are available from the corresponding author on reasonable request.

\section{Ethics approval and consent to participate}

This study was reviewed and approved by the British Columbia Cancer Research Ethics Board Consent for publication:

\section{Consent for publication}

Not applicable.

\section{Competing interests}

ST reports personal fees from Bayer, outside the submitted work. AN reports grants from Varian Medical Systems, outside the submitted work.

\section{Author details}

'Department of Radiation Oncology, BC Cancer, Vancouver Centre, Vancouver, British Columbia, Canada. ${ }^{2}$ Cancer Surveillance and Outcomes, BC Cancer, Vancouver Centre, Vancouver, British Columbia, Canada. ${ }^{3}$ Department of Nuclear Medicine, BC Cancer, Vancouver Centre, Vancouver, British Columbia, Canada.

Received: 29 November 2019 Accepted: 19 May 2020

Published online: 01 June 2020

\section{References}

1. Darby S, McGale P, Correa C, Taylor C, Arriagada R, Clarke M, Cutter D, Davies C, Ewertz M, Godwin J, et al. Effect of radiotherapy after breastconserving surgery on 10-year recurrence and 15-year breast cancer death: meta-analysis of individual patient data for 10,801 women in 17 randomised trials. Lancet. 2011;378(9804):1707-16.

2. Early Breast Cancer Trialists' Collaborative G. Effect of radiotherapy after mastectomy and axillary surgery on 10-year recurrence and 20-year breast cancer mortality: meta-analysis of individual patient data for 8135 women in 22 randomised trials. Lancet. 2014;383(9935):2127-35.

3. Overgaard M, Jensen MB, Overgaard J, Hansen PS, Rose C, Andersson M, Kamby C, Kjaer M, Gadeberg CC, Rasmussen BB, et al. Postoperative radiotherapy in high-risk postmenopausal breast-cancer patients given adjuvant tamoxifen: Danish Breast Cancer Cooperative Group DBCG 82C randomised trial. Lancet. 1999;353(9165):1641-8.

4. Nielsen HM, Overgaard M, Grau C, Jensen AR, Overgaard J. Study of failure pattern among high-risk breast cancer patients with or without postmastectomy radiotherapy in addition to adjuvant systemic therapy: long-term results from the Danish breast Cancer cooperative group DBCG $82 \mathrm{~b}$ and $\mathrm{c}$ randomized studies. J Clin Oncol. 2006;24(15):2268-75.

5. Ragaz J, Olivotto IA, Spinelli JJ, Phillips N, Jackson SM, Wilson KS, Knowling MA, Coppin CM, Weir L, Gelmon K, et al. Locoregional radiation therapy in patients with high-risk breast cancer receiving adjuvant chemotherapy: 20-year results of the British Columbia randomized trial. J Natl Cancer Inst. 2005;97(2):116-26.

6. Whelan TJ, Olivotto IA, Parulekar WR, Ackerman I, Chua BH, Nabid A, Vallis KA, White JR, Rousseau P, Fortin A, et al. Regional nodal irradiation in earlystage breast Cancer. N Engl J Med. 2015;373(4):307-16.

7. Poortmans PM, Collette S, Kirkove C, Van Limbergen E, Budach V, Struikmans H, Collette L, Fourquet A, Maingon P, Valli M, et al. Internal mammary and medial supraclavicular irradiation in breast Cancer. N Engl J Med. 2015;373(4):317-27.

8. Thorsen LB, Offersen BV, Dano H, Berg M, Jensen I, Pedersen AN, Zimmermann SJ, Brodersen HJ, Overgaard M, Overgaard J. DBCG-IMN: a population-based cohort study on the effect of internal mammary node irradiation in early node-positive breast Cancer. J Clin Oncol. 2016;34(4):31420

9. Li XA, Tai A, Arthur DW, Buchholz TA, Macdonald S, Marks LB, Moran JM, Pierce $L$, Rabinovitch R, Taghian A, et al. Variability of target and normal structure delineation for breast cancer radiotherapy: an RTOG multiinstitutional and multiobserver study. Int J Radiat Oncol Biol Phys. 2009; 73(3):944-51.

10. RTOG Breast Atlas. https://www.rtog.org/CoreLab/ContouringAtlases.aspx. Accessed 16 Apr 2020.

11. Offersen BV, Boersma LJ, Kirkove C, Hol S, Aznar MC, Biete Sola A, Kirova YM, Pignol JP, Remouchamps V, Verhoeven K, et al. ESTRO consensus guideline on target volume delineation for elective radiation therapy of early stage breast cancer. Radiother Oncol. 2015;114(1):3-10.

12. Offersen BV, Boersma LJ, Kirkove C, Hol S, Aznar MC, Sola AB, Kirova YM Pignol JP, Remouchamps V, Verhoeven $\mathrm{K}$, et al. ESTRO consensus guideline on target volume delineation for elective radiation therapy of early stage breast cancer, version 1.1. Radiother Oncol. 2016;118(1):205-8.

13. Brown LC, Diehn FE, Boughey JC, Childs SK, Park SS, Yan ES, Petersen IA, Mutter RW. Delineation of supraclavicular target volumes in breast Cancer radiation therapy. Int J Radiat Oncol Biol Phys. 2015;92(3):642-9.

14. Gentile MS, Usman AA, Neuschler El, Sathiaseelan V, Hayes JP, Small W Jr. Contouring guidelines for the axillary lymph nodes for the delivery of radiation therapy in breast Cancer: evaluation of the RTOG breast Cancer atlas. Int J Radiat Oncol Biol Phys. 2015;93(2):257-65.

15. Jing H, Wang SL, Li J, Xue M, Xiong ZK, Jin J, Wang WH, Song YW, Liu YP, Ren $\mathrm{H}$, et al. Mapping patterns of Ipsilateral supraclavicular nodal metastases in breast Cancer: rethinking the clinical target volume for high-risk patients. Int J Radiat Oncol Biol Phys. 2015;93(2):268-76.

16. Jethwa KR, Kahila MM, Hunt KN, Brown LC, Corbin KS, Park SS, Yan ES, Boughey JC, Mutter RW. Delineation of internal mammary nodal target volumes in breast Cancer radiation therapy. Int J Radiat Oncol Biol Phys. 2017;97(4):762-9.

17. Chang JS, Byun HK, Kim JW, Kim KH, Lee J, Cho Y, Lee IJ, Keum KC, Suh CO, Kim YB. Three-dimensional analysis of patterns of locoregional recurrence after treatment in breast cancer patients: validation of the ESTRO consensus guideline on target volume. Radiother Oncol. 2017;122(1):24-9.

18. Chang JS, Lee J, Chun M, Shin KH, Park W, Lee JH, Kim JH, Yoon WS, Lee IJ, Kim J, et al. Mapping patterns of locoregional recurrence following contemporary treatment with radiation therapy for breast cancer: a multiinstitutional validation study of the ESTRO consensus guideline on clinical target volume. Radiother Oncol. 2018;126(1):139-47.

19. Borm KJ, Voppichler J, Dusberg M, Oechsner M, Vag T, Weber W, Combs SE, Duma MN. FDG / PET-CT based lymph node atlas in breast cancer patients. Int J Radiat Oncol Biol Phys. 2019;103(3):574-82.

20. DeSelm C, Yang TJ, Cahlon O, Tisnado J, Khan AJ, Gillespie EF, Siu CT, Powell SN, Ho AY. A 3-dimensional mapping analysis of regional nodal recurrences in breast Cancer. Int J Radiat Oncol Biol Phys. 2019;103(3):58391.

21. Almahariq MF, Maywood MJ, Levitin RB, Squires BS, Jawad MS, Chen PY, Gustafson GS, Dilworth JT. Mapping of metastatic level I axillary lymph nodes in patients with newly diagnosed breast Cancer. Int J Radiat Oncol Biol Phys. 2020;106(4):811-20.

22. Kowalski ES, Feigenberg SJ, Cohen J, Fellows Z, Vadnais P, Rice S, Mishra MV Molitoris JK, Nichols EM, Snider JW. 3rd: Optimal Target Delineation and Treatment Techniques in the Era of Conformal Photon and Proton Breast and Regional Nodal Irradiation. Pract Radiat Oncol. 2020;10(3):174-82. https://doi.org/10.1016/j.prro.2019.11.010.

23. Groheux D, Espie M, Giacchetti S, Hindie E. Performance of FDG PET/CT in the clinical management of breast cancer. Radiology. 2013;266(2): 388-405.

24. Radan L, Ben-Haim S, Bar-Shalom R, Guralnik L, Israel O. The role of FDGPET/CT in suspected recurrence of breast cancer. Cancer. 2006;107(11):254551.

25. RADCOMP Breast Atlas. https://www.rtog.org/CoreLab/ContouringAtlases/ RADCOMPBreastAtlas.aspx. Accessed 16 Apr 2020.

26. Werner-Wasik M, Nelson AD, Choi W, Arai Y, Faulhaber PF, Kang P, Almeida FD, Xiao $Y$, Ohri N, Brockway $K D$, et al. What is the best way to contour lung tumors on PET scans? Multiobserver validation of a gradient-based method using a NSCLC digital PET phantom. Int J Radiat Oncol Biol Phys. 2012;82(3):1164-71. 
27. Schacht DV, Drukker K, Pak I, Abe H, Giger ML. Using quantitative image analysis to classify axillary lymph nodes on breast MRl: a new application for the Z 0011 era. Eur J Radiol. 2015;84(3):392-7.

28. Fusco R, Sansone M, Granata V, Di Bonito M, Avino F, Catalano O, Botti G, Petrillo A. Use of quantitative morphological and functional features for assessment of axillary lymph node in breast dynamic contrast-enhanced magnetic resonance imaging. Biomed Res Int. 2018;2018:2610801.

29. Eubank WB, Mankoff DA, Takasugi J, Vesselle H, Eary JF, Shanley TJ, Gralow JR, Charlop A, Ellis GK, Lindsley KL, et al. 18fluorodeoxyglucose positron emission tomography to detect mediastinal or internal mammary metastases in breast cancer. J Clin Oncol. 2001;19(15):3516-23.

30. Heusner TA, Kuemmel $\mathrm{S}$, Hahn $\mathrm{S}$, Koeninger A, Otterbach F, Hamami ME, Kimmig KR, Forsting M, Bockisch A, Antoch $G$, et al. Diagnostic value of fulldose FDG PET/CT for axillary lymph node staging in breast cancer patients. Eur J Nucl Med Mol Imaging. 2009:36(10):1543-50.

31. Coen JJ, Taghian AG, Kachnic LA, Assaad SI, Powell SN. Risk of lymphedema after regional nodal irradiation with breast conservation therapy. Int J Radiat Oncol Biol Phys. 2003;55(5):1209-15.

32. Gujral DM, Chahal N, Senior R, Harrington K, Nutting CM. Radiation-induced carotid artery atherosclerosis. Radiother Oncol. 2014;110(1):31-8.

33. Grantzau T, Mellemkjaer L, Overgaard J. Second primary cancers after adjuvant radiotherapy in early breast cancer patients: a national population based study under the Danish breast Cancer cooperative group (DBCG). Radiother Oncol. 2013;106(1):42-9.

34. Hayes SB, Freedman GM, Li T, Anderson PR, Ross E. Does axillary boost increase lymphedema compared with supraclavicular radiation alone after breast conservation? Int J Radiat Oncol Biol Phys. 2008;72(5):1449-55.

35. Gee H, Moses L, Stuart K, Nahar N, Tiver K, Wang T, Ward R, Ahern V. Contouring consensus guidelines in breast cancer radiotherapy: comparison and systematic review of patterns of failure. J Med Imaging Radiat Oncol. 2019;63:102-15

36. Loganadane GK, Truong PT, Taghian AG, Tešanović D, Jiang M, Geara F, Moran MS, Belkacemi Y, et al. Int J Radiat Oncol Biol Phys. 2020. https://doi. org/10.1016/j.jprobp.2020.04.012

\section{Publisher's Note}

Springer Nature remains neutral with regard to jurisdictional claims in published maps and institutional affiliations.

Ready to submit your research? Choose BMC and benefit from:

- fast, convenient online submission

- thorough peer review by experienced researchers in your field

- rapid publication on acceptance

- support for research data, including large and complex data types

- gold Open Access which fosters wider collaboration and increased citations

- maximum visibility for your research: over $100 \mathrm{M}$ website views per year

At BMC, research is always in progress.

Learn more biomedcentral.com/submissions 